\title{
Pulsed Electrostatic Field (PESF) and Patients with Type 2 Diabetes Undergoing Hemodialysis: Endothelial Dysfunction and Altered Hemostasis
}

\author{
Liani $\mathbf{M}^{1 *}$, Trabassi $\mathrm{E}^{2}$, Di Luzio $\mathrm{R}^{3}$, Tripaldi $\mathrm{R}^{4}$, Lattanzio $\mathrm{S}^{4}$ and \\ Liani $\mathbf{R}^{4}$ \\ 1Former Director Nephrology and Dialysis, P.O. "St. Maximus", Penne (PE) AUSL \\ Pescara, Italy \\ Research Article \\ Volume 2 Issue 2 \\ Received Date: February 22, 2018 \\ Published Date: March 21, 2018 \\ DOI: $10.23880 /$ mjccs- 16000140 \\ ${ }^{2}$ Nephrology and Dialysis, "St. Maximus", Penne (PE) AUSL Pescara, Italy \\ ${ }^{3}$ Health Directorate P.O. "San Massimo", Penne (PE), AUSL Pescara, Italy \\ ${ }^{4}$ Internal Medicine and Center of Aging Sciences and Translational Medicine (CeSI-MeT), "G. d'Annunzio" University of \\ Chieti-Pescara, Italy
}

*Corresponding author: Mario Liani, Former Director Nephrology and Dialysis, P.O. "St. Maximus", Penne (PE) AUSL Pescara, via Manzoni, 9 - 66020 San Giovanni Teatino (Chieti), Italy, Tel: 3337312253; E-mail: mario.liani@tin.it

\section{Abstract}

Backgrounds: Patients with chronic kidney disease and with diabetes mellitus type 2 have a high incidence of micro and macroangiopathy. Availability impaired of Nitric Oxide (NO) endogenous, consequent to endothelial dysfunction, can lead to peripheral vasoconstriction, altered hemostasis, enhanced platelet activation and altered permeability of vascular wall.

Methods: Two groups of patients with type 2 diabetes, ischemic foot ulcers and receiving hemodialysis, were exposed or not to Pulsed Electrostatic Field Therapy (PESF). We also valued if the effects of PESF treatment on wound healing were influenced by the presence or not of obesity.

Results: We found statistically significant differences from controls in body weight, systolic and diastolic pressure, heart rate and frequency of peripheral pulsations. Mean blood NO levels were significantly elevated in the treated group. Groups of patients obese and not obese treated with PESF there was a highly significant increases in the rate of wound healing as determined by ulcer area but not in untreated patients.

Conclusions: Positive changes were found in body weight, cardiovascular function and platelet behavior. PESF is a promising new technique for the management of diabetic foot ulcers and further studies appear to be warranted. 


\section{Medical Journal of Clinical Trials \& Case Studies}

Keywords: PESF; Foot ulcers; Diabetes; Hemodialysis; Nitric Oxide (NO)

Abbreviations: PESF: Pulsed Electrostatic Field; T2DM: Type 2 Diabetes Mellitus; CLI: Critical Ischemia; CKD: Chronic Kidney Disease; BMR: Basic Metabolic Rate; DF: Dietary Fiber; FP: Frequency of Peripheral

\section{Introduction}

Type 2 diabetes mellitus (T2DM) is a metabolic disorder with increased platelet activation and altered hemostasis that predisposes to thrombotic events and despite careful control of glucose is often associated with critical ischemia (CLI) that can lead to the development of ischemic ulcers with high risk of amputation [1-4].

Patients with T2DM are severely affected both by macro-, microangiopathy and by altered hemostasis. Vascular diseases generate a chronic reduction of tissue oxygenation at the ischemic site and the lesion may be exacerbated both by pathological changes in the local endothelium and by abnormalities of the erythrocytes [5].

Thrombocytopathy has been attributed or extrinsic or intrinsic factors to platelets including the formation of active substances independent COX1 [6]. Tissue perfusion is worsened by impaired plasticity and an increased tendency to aggregation of red blood cells and rouleaux formation leading to occlusion of the microvasculature [7].

It has been shown that where there is a degree of vascular reactivity this is frequently accompanied by changes of electrical charges both on the endothelium and on the erythrocyte surface [8]. The atherosclerosis risk factors, as hypercholesterolemia (LDL), hyperglycemia, inflammation, salt excess and altered shear stress can damage and degrade glycocalyx that leading to endothelial dysfunction in patients with diabetes mellitus and chronic kidney disease (CKD) [9-11].

The functional alteration of macro- and microcirculation is a clinically significant problem in patients with T2DM undergoing haemodyalisis [12]. The CKD is characterized by a state of chronic inflammation which contributes to an altered interaction and function between platelets, leukocytes and endothelial cells [12].
Different hemodialysis membranes activate complement and maintain a chronic inflammatory state [13]. Patients with CKD with and T2DM show high frequency of mortality for cardiovascular events [14].

Patients with CKD without T2DM have a reduced platelet aggregation and have a high frequency of cardiovascular events. In these patients, impaired primary hemostasis has been attributed to altered expression of platelet surface receptors, GPIb and GPIIb/IIIa [15]. Patients with CKD and with T2DM have enhanced platelet activation [16]. In patients with T2DM it is not known whether prothrombotic state derives from an extra or intra- platelet factor $[17,18]$. Hemostasis is affected by extracorporeal circuit in patients in hemodialysis $[19,20]$.

Studies have demonstrated that patients with CKD show increased insulin resistance, oxidative stress and endothelial dysfunction [11,21,22]. The reduced availability of nitric oxide endogenous, consequent to endothelial dysfunction, can lead to peripheral vasoconstriction, altered hemostasis, enhanced platelet activation and altered permeability $[23,24]$.

The electrostatic field can stimulate motility in the microcirculation, increase the basic metabolic rate (BMR) and tissutal perfusion [25,26]. Patients with foot ulcers have a poor long term prognosis with a 3yr mortality of $35-40 \%$ [27]. In a previous study we have shown that these changes induced by Pulsating Electrostatic Field (PESF) therapy could improve outcomes in refractory foot ulcers in patients with T2DM [28]. We have extended our earlier study to determine if PESF therapy could induce benefit in patients with T2DM and CKD undergoing dialysis, if there were differences between obese or not patients and if there were relationships between nitric oxide levels, exposure to PESF and some comorbidity of disease.

We also looked at potential correlations between expression of platelet surface receptors GPIb and GPIIb/GPIIIa and nitric oxide. We wished to test the hypothesis that a positive effect on flow motion and platelet pathology might shed new light on the mechanisms involved in the key pro-thrombotic indicators in these patients. 


\section{Medical Journal of Clinical Trials \& Case Studies}

\section{Materials and Methods}

\section{Patients}

Between January 2009 and July 2015 were enrolled 90 subjects with chronic renal failure, T2DM, poor perfusion and ischemic ulcers foot Grade 1, Stage A, B, C, D, classified according to the Texas University and underwent to regular hemodialysis in Nephrology and Dialysis Unit, P.O. "San Massimo", Penne, Italy [29].

\section{Study Design and Randomization}

All patients had their metabolic state under medical supervision and during the study have not changed their dialysis therapy, medication and local treatment. Ultrasonography was performed on all patients and none had vascular obstruction indicating that microvascular ischemia was a likely factor in the ulcer production. Patients were divided randomly into two groups. Group A was composed of 45 subjects (mean age $=72.51 \pm 12.80 ; 25$ men and 20 women) and group B of 45 subjects (mean age $=75.02 \pm 8.44 ; 23$ men and 22 women). The difference in HbA1c between group A $(6.43 \pm 0.77 \%)$ and B $(6.65 \pm 1.09 \%)$ was not statistically significant. Group A and $\mathrm{B}$ had the same dialysis efficacy as assessed by $\mathrm{Kt} / \mathrm{V}$ computation (group A Kt/V=1.27 \pm 0.19 ; group B $\mathrm{Kt} / \mathrm{V}=1.30 \pm 0.20$ ). Before starting any intervention we brought the blood glucose levels of all patients to euglycemic levels by giving them personalized dietary programs, dietary fiber (DF) with regular monitoring of blood glucose levels.

\section{Procedures}

Patients in group A were treated with PESF therapy generated by medical devices (Body Care 9000 medical device, Akern srl, Via Lisboa 32-4, 50065, Pontassieve (FI), Italy) and group B were exposed to simulated PESF using the same conditions. The treatment included a total of 13 sessions, three times a week on alternate days and with 30 minutes exposure (Figure 1). The intensity of each PESF cycle was based on the patient's body cell mass as determined using a phase sensitive bioelectrical impedance device (BIA 101; Akern srl, Pontassieve, Italy) [26]. In Figure 1 we illustrate the method of application PESF. Weight pre and post dialysis, weight gain, systolic and diastolic pressure, heart rate, $\mathrm{SpO}_{2}$ extraction at the level of the ulcerated foot and $\mathrm{SpO}_{2}$ extraction and Frequency of Peripheral (FP) pulsations at the level of hand free distant from any AV fistula (Ohmeda Pulse Oximeter- 512F) were valued in all patients at baseline and at the end of PESF treatment.

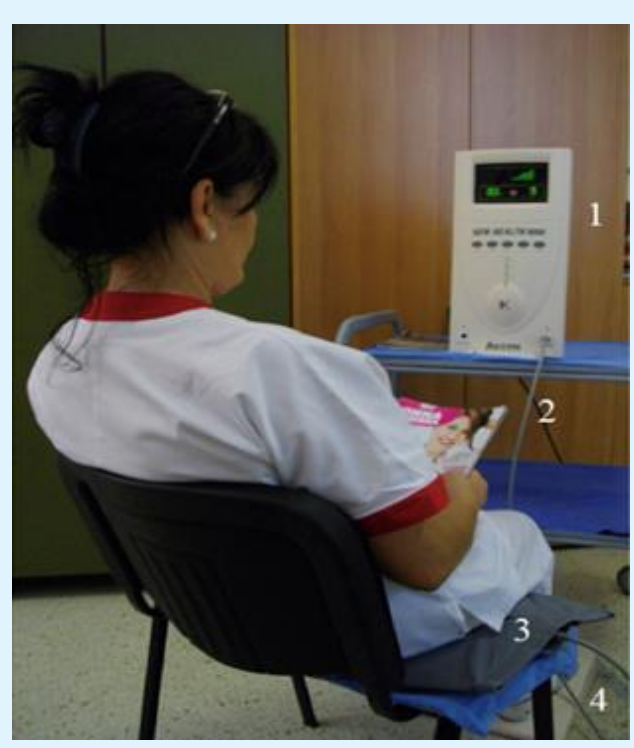

Figure 1: PESF Treatment (New Health 9000Akern/Saeik, Florence Italy):

1. Pulsating Electros-tatic Field (PESF) generator.

2. Highly insulated lead.

3. Ion mat that transmits the electrostatic field.

4. Insulating mat.

We also evaluated a possible influence of obesity on the rate of ulcer healing. Group A was composed by 24 obese $\left(\mathrm{BMI}<30 \mathrm{~kg} / \mathrm{m}^{2}\right)$ subjects and 21 no-obese $\left(\mathrm{BMI}<30 \mathrm{~kg} / \mathrm{m}^{2}\right)$, while group $\mathrm{B}$ was composed by 20 obese $\left(\mathrm{BMI}<30 \mathrm{~kg} / \mathrm{m}^{2}\right)$ and 25 no-obese $\left(\mathrm{BMI}<30 \mathrm{~kg} / \mathrm{m}^{2}\right)$. We collected peripheral blood samples at baseline for all participants, and in the end only in patients who have agreed to perform the second collection (group $A \mathrm{n}=27$, group B $n=25$ ). Blood sampling for the platelet studies was taken before dialysis by venipuncture with 16G needle and without the use of a tourniquet. Samples were stored in citrated vacutainer and analyzed immediately for GPIb and GPIIb/IIIa. The expression of the receptors was determined by cytometry FACS flow using specific monoclonal antibodies CD42b-FITC (specific for GPIb) and CD41a-FITC (specific for GPIIb/IIIa that binds fibrinogen).We have assayed serum nitric oxide levels using a commercial kit ELISA (R\&D Systems, Inc. 614 McKinley Place NE Minneapolis, MN 55413).

NO assay is based on the enzymatic conversion of nitrate to nitrite by nitrate reductase. This type of reaction develops in two phases; the first phase is a nitrogenation reaction in which $\mathrm{NO}_{2}$ in an acidified environment produces a nitrosant agent and in a second phase in which the reaction with sulfanilic acid produces the diazonium ion. This ion is then coupled to $\mathrm{N}$-(1-naphthyl) 


\section{Medical Journal of Clinical Trials \& Case Studies}

ethylenediamine to form a nitrogen derivate chromophore absorbing at 540-570 $\mathrm{nm}$ [30]. Ulcer healing was assessed by measuring the ulcerated surface (sq.cm.) photographically and calculated using a 10 megapixel counting system. This technique was considered to be more reproducible and less disturbing to the patient than determining ulcer depth. Wound surface area was measured before PESF treatment and after 13 sessions of PESF.

\section{Statistical Analyses}

The statistical significance between means for all measurements was assessed using Student's t test for matched pairs ( $p$ value $<0.05$ was considered to be significant) and analysis of Variance (ANOVA). The study protocol was approved by the Hospital Management of the Riuniti Hospital of Pescara, and patients provided written informed consent. All patients enrolled in the study were given detailed explanations, both verbal and written, describing the aim of the study, the technical characteristics of the equipment and the operating procedures. After this information was provided each participant was asked to give informed consent. Patients were told they were free to withdraw from the study at any point without the need to give a reason.

\section{Results}

As expected all hemodialysis patients showed a statistically significant reduction in body weight pre- and post- hemodialisys HD, systolic and diastolic blood pressure and heart rate before and after PESF cycle (Table 1). We did not find $\mathrm{SpO}_{2} \%$ differences between the two groups, at the level of the hand or foot, but we observed a significant increase in FP at the level of the hand before and after PESF. We found a statistically significant increased nitric oxide levels only in group treated with PESF (Table 1). We observed a statistically significant change in expression (Mean Flow) of platelet receptors in the studio and in detail a significant reduction GPIIb/IIIa $(\mathrm{p}=0.004)$ and increased GPIb ( $\mathrm{p}=0.006)$ only in the group treated (Table 1). Only in the group treated with PESF we had a significant reduction in the fluorescence percentage (\%) of GPIIb/IIIa receptor.

\begin{tabular}{|c|c|c|c|c|c|c|}
\hline \multirow{2}{*}{$\begin{array}{c}\text { Type 2 } \\
\text { Diabetes }\end{array}$} & \multicolumn{2}{|c|}{ Group A (n=45) } & \multicolumn{2}{c|}{ Group B (n=45) } \\
\cline { 2 - 6 } & $\begin{array}{c}\text { Pre PESF } \\
\text { Mean } \pm \text { SD }\end{array}$ & $\begin{array}{c}\text { Post PESF } \\
\text { Mean } \pm \text { SD }\end{array}$ & $\mathbf{p}$ & $\begin{array}{c}\text { Pre } \\
\text { Mean } \pm \text { SD }\end{array}$ & Mean \pm SD & p \\
\hline Weight Pre HD & $73.14 \pm 14.90$ & $72.15 \pm 14.63$ & 0.01 & $70.59 \pm 9.42$ & $70.46 \pm 9.41$ & NS \\
\hline WeightPost HD & $71.12 \pm 14.20$ & $70.35 \pm 14.30$ & 0.03 & $68.54 \pm 9.13$ & $68.53 \pm 9.08$ & NS \\
\hline Weight Gain & $1.83 \pm 0.93$ & $1.82 \pm 1.05$ & NS & $1.87 \pm 0.78$ & $2.02 \pm 0.77$ & NS \\
\hline Systolic Pressure & $145.56 \pm 24.28$ & $137.67 \pm 22.40$ & 0.001 & $141.00 \pm 23.93$ & $141.87 \pm 19.47$ & NS \\
\hline Diastolic Pressure & $75.07 \pm 12.95$ & $70.20 \pm 12.76$ & 0.0002 & $72.60 \pm 10.92$ & $72.89 \pm 10.64$ & NS \\
\hline Heart Rate & $74.04 \pm 9.70$ & $70.71 \pm 7.88$ & 0.0018 & $72.492 \pm 10.63$ & $72.20 \pm 10.21$ & NS \\
\hline \%Sp0 Hand & $94.84 \pm 3.69$ & $95.49 \pm 4.23$ & NS & $95.40 \pm 3.22$ & $95.78 \pm 2.70$ & NS \\
\hline \%Sp0 Foot & $95.00 \pm 4.42$ & $95.69 \pm 4.56$ & NS & $96.00 \pm 2.85$ & $95.49 \pm 3.12$ & NS \\
\hline FP & $70.99 \pm 12.22$ & $75.55 \pm 11.84$ & 0.008 & $74.06 . \pm 14$. & $76.34 . \pm 12.79$ & NS \\
\hline Nitric Oxide (NO) & $33.32 \pm 8.21$ & $46.93 \pm 16.73$ & 0.0004 & $32.40 \pm 12.49$ & $30.14 \pm 13.54$ & NS \\
\hline GPIIb/IIIa (Mean) & $289.01 \pm 100.13$ & $243.44 \pm 67.79$ & 0.004 & $268.76 \pm 82.83$ & $246.19 \pm 55.29$ & NS \\
\hline GPIb (Mean) & $161.08 \pm 56.68$ & $203.34 \pm 89.18$ & 0.0067 & $199.86 \pm 73.63$ & $194.71 \pm 38.90$ & NS \\
\hline GPIIb/IIIa (\%) & $98.81 \pm 1.18$ & $96.99 \pm 5.61$ & 0.027 & $96.68 \pm 2.69$ & $96.44 \pm 3.74$ & NS \\
\hline GPIb (\%) & $87.44 \pm 12.41$ & $92.25 \pm 6.53$ & 0.14 & $88.75 \pm 8.59$ & $90.83 \pm 6.61$ & NS \\
\hline
\end{tabular}

Table 1: Patients with T2DM and with ulcers in hemodialysis were divided randomly into two groups: A (n=45) treated with PESF (Pulsed Electrostatic Field Therapy) and B (n=45) untreated. 


\section{Medical Journal of Clinical Trials \& Case Studies}

In both groups of patients obese and non-obese treated with PESF there was a highly significant increase in the rate of wound healing as determined by ulcer area (Table
2) but not in untreated patients. No adverse effects from PESF treatment were reported by patients in either group

\begin{tabular}{|c|c|c|c|c|}
\hline \multirow{2}{*}{\multicolumn{2}{|c|}{$\begin{array}{c}\text { Diabetes Mellitus } \\
\text { Type } 2\end{array}$}} & \multicolumn{3}{|c|}{ Area Of Ulcers $\left(\mathrm{cm}^{2}\right)$} \\
\hline & & Pre & Post & $\mathbf{P}$ \\
\hline \multirow{2}{*}{$\begin{array}{c}\text { Group A } \\
\text { PESF }\end{array}$} & $\begin{array}{c}\text { OBESE } \\
(n=24) \\
\text { BMI }>30 \mathrm{Kg} / \mathrm{m} 2 \\
\end{array}$ & $3.56 \pm 3.26$ & $1.96 \pm 2.37$ & 0.00003 \\
\hline & $\begin{array}{c}\text { NO OBESE } \\
(n=21)\end{array}$ & $4.54 \pm 8.03$ & $3.80 \pm 7.11$ & 0.0002 \\
\hline \multirow{2}{*}{$\begin{array}{l}\text { Group B } \\
\text { No PESF }\end{array}$} & $\begin{array}{c}\text { OBESE } \\
(\mathrm{n}=20) \\
\text { BMI }>30 \mathrm{Kg} / \mathrm{m} 2 \\
\end{array}$ & $4.35 \pm 3.48$ & $3.88 \pm 3.00$ & NS \\
\hline & $\begin{array}{c}\text { NO OBESE }(n=25) \\
\text { BMI }<30 \mathrm{Kg} / \mathrm{m} 2\end{array}$ & $2.40 \pm 1.42$ & $2.46 \pm 2.02$ & NS \\
\hline
\end{tabular}

Table 2: To evaluate a possible influence of obesity on the rate of ulcer healing (area of ulcer, $\mathrm{cm}^{2}$ ) Induced by treatment or un-treatment PESF: group A was composed by obese $\left(\mathrm{n}=24, \mathrm{BMI}>30 \mathrm{~kg} / \mathrm{m}^{2}\right)$ and no-obese $\left(\mathrm{n}=21, \mathrm{BMI}<30 \mathrm{~kg} / \mathrm{m}^{2}\right)$ subjects, while group B was composed by ob-ese $\left(\mathrm{n}=20\right.$, BMI $\left.>30 \mathrm{~kg} / \mathrm{m}^{2}\right)$ no-obese $\left(\mathrm{n}=25 ; \mathrm{BMI}<30 \mathrm{~kg} / \mathrm{m}^{2}\right)$ subjects. PESF Pulsed Electrostatic Field Therapy; BMI - Body Mass Index $\left(\mathrm{Kg} / \mathrm{m}^{2}\right)$.

\section{Discussion}

The pioneering work of Becker in the second half of the last century, summarized in his book "The Body Electric" provided evidence that during the process of wounding and wound healing there were changes in the electric fields at the wound skin [31]. More recently Nuccitelli, et al. have shown that a negative field exists within a skin wound that gradually disappears during healing and they have attributed this chemotactic effect to the electrostatic field [32]. Others attribute the results obtained with PESF to a disaggregating effect on red blood cells and vasomotion $[33,34]$. There is evidence of alterations in the state of the endothelium in vessels associated with ulcers [35]. Patients with T2DM and chronic renal failure are characterized by endothelial dysfunction that often is associated with insulin resistance, impaired hemostasis, and reduction in vasomotor tone, increased vascular permeability and impaired immune function [36].

When an electric field is applied to cells in culture several biological phenomena have been observed; not only they did change their morphology and their orientation, but they increased the production of VEGF [37]. These effects could be due to a change of membrane potential and of mitochondrial function and to generation of nitric oxide [38]. A recent review has highlighted that only studies that used electrical stimulation with AC or DC currents have obtained healing of ulcers [39]. In previous study, patients with T2DM and with foot ulcers, but not in hemodialysis, showed an improved rate of healing and a reduction in pain levels after PESF treatment [28]. We have examined platelet surface receptors (GPIIb/IIIa and GPIb) in hemodialysis patients with AV fistulae and correlated with the incidence of clogging of fistulas [40].

In this study the significant variation of platelet surface markers induced by PESF treatment suggests that these factors may play a role in the healing of ischemic foot ulcers. The treatment of ulcerated tissues with oxygen rich environments (hyperbaric chamber) induces healing but benefits don't are long lasting [41]. In our study there was no increase in tissue oxygenation as measured by $\mathrm{SpO}_{2}$ levels but enhanced of FP. We have demonstrated that PESF treatment of diabetic foot ulcers in patients subjected to dialysis when combined with conventional treatment can accelerate wound healing but the mechanisms responsible still require further investigation.

We postulate that there are multiple factors involved that include an effect on the prevention and/or disaggregation erythrocyte rouleaux formation that may affect capillary blood flow as shown by the drop in diastolic pressure during PESF exposure. A plausible explanation for these changes is that the increase in circulating NO is responsible for the beneficial effects observed. In our study the acceleration of ulcer healing does not seem to be affected by the different body composition (obese or not) of our patients. At the moment 


\section{Medical Journal of Clinical Trials \& Case Studies}

we are not able to give a convincing interpretation of this phenomenon. The results from this study demonstrate that there is a potential role for PESF therapy in the management of diabetic ulcers in patients undergoing hemodialysis and this view finds support from the similar results in non-hemodialysis patients reported by us previously.

\section{Conclusion}

Endothelial dysfunction may be caused by loss of structural integrity of the cells. The glycocalyx is an organized network consisting of glycoproteins, proteoglycans and glycosaminoglycans (GAGs) that covers the surface of the endothelium and is an integral part of the membrane itself. Structural lesions of the glycocalyx deprive the endothelial cell of an important protection mechanism. The glycocalyx in fact is a physiological barrier for the protection with negative charges and contributes to the flow of blood, modulates the adhesion of leukocytes and platelets, regulates the selective permeability and averages the pressure signals, chemical and enzymatic [42-44]. Some attribute the appearance of edemas on the occasion of secondary inflammation to impairment of the integrity of the glycocalyx and to loss of selectivity function $[45,46]$.

If it is reasonable to assume that structural changes induced by external or internal mechanisms may compromise cell function then it is safe to assume that even the impairment of negative electrical charges, an integral part of the glycocalyx, may be associated with loss of some functions of our body. The administration of negative electric charges improves some functions of endothelial cells with structural alteration of the glycocalyx. In patients with T2DM and CKD with microalbuminuria the thickness of the glycocalyx is about half compared with healthy controls [47]. To date there is no scientific evidence showing that antioxidants, statins and corticosteroids are able to preserve the integrity of the glycocalyx [48]. Previously other studies had highlighted, in patients with diabetes mellitus, a significant correlation between polyanions on the surface of red blood cells and retinopathy underlining how electric charges may affect the aggregation of reticulocytes and microangiopathy. Recently others have attributed the angiogenesis to the microvesicles released from membranes of endothelial progenitors cells (MVs) with determinant role of eNOS system $[49,50]$.

It seems obvious that, despite the indisputable clinical and functional results of therapies so far used, the effects obtained cannot be considered final. This justifies widely, given the enormous complexity of the problem, the use of alternative therapies and at the same time complementary. Some authors attribute endothelial dysfunction and the atherogenic pathogenesis mainly to a permanent state of inflammation [51]. Inflammation induces pathological changes in the glycolalyx and the patients with T2DM and CKD have an inflammation chronic state [52,53]. It appears evident that, in diabetes mellitus, the function of the microcirculation is conditioned by the degree of endothelial dysfunction where is not alien the impairment of the structure of the glycocalyx. We hypothesize that the use of PESF can intervene on the altered electrical charges of glycocalyx and can promote improved endothelial response to conventional therapies. The administration of negative electrostatic charges can be considered as a submolecular therapy can also improve the effectiveness of drugs [54].

The reduction in systolic and diastolic blood pressure, the primary changes on hemostasis and the increase in NO suggest a possible improved effect on functional of the endothelium. Our intention was to induce favorable clinical results and to improve, in T2DM patients with vascular disease, the tissue perfusion [55]. The results from this study demonstrate that there is a potential role for PESF therapy in the management of diabetic ulcers in patients with T2DM and undergoing hemodialysis and this view finds support from the similar results in nonhemodialysis patients reported by us and others previously. A major advantage with the use of PESF when compared with conventional treatments is the lack of adverse effects from this non-invasive therapy and its ease of application thus it is a suitable technique for home use by appropriately selected patients with consequent cost saving. These advantages may improve compliance in patients undergoing home treatment.

\section{Acknowledgements}

The authors thank Eng T. Talluri of Akern srl, Italy for advice on the application of the New Health 9000 and Lister R (Phylax,- Beaconsfield, HP9 2AS, U.K.) for editorial assistance.

\section{References}

1. Vella A, Jensen MD, Nair KS (2016) Eulogy for the Metabolic Clinical Investigator?. Diabetes 65(10): 2821-2823.

2. Gregg EW, Li Y, Wang J, Rios Burrows N, Ali MK, et al. (2014) Changes in diabetes-related complications in 


\section{Medical Journal of Clinical Trials \& Case Studies}

the United States, 1990-2010. N Eng J Med 370: 1514-1523.

3. DavìG, PatronoC (2007) Platelet activation and atherothrombosis. N Engl J Med 357(24): 2482-2494.

4. Armstrong DG, Lavery LA, HarklessLB (1998) Validation of diabetic wound classification system. The contribution of depth, infection and ischemia to risk of amputation. Diabetes Care 21(5): 855-859.

5. Szablewski L, Sulima A (2016) The structural and functional changes of blood cells and molecular components in diabetes mellitus. Biol Chem 398(9): 411-423.

6. Davì G, Ciabattoni $\mathrm{G}$, Consoli $\mathrm{A}$, Mezzetti $\mathrm{A}$, Falco $\mathrm{A}$, et al. (1999) In vivo formation of 8-iso-prostaglandin f2 alpha and platelet activation in diabetes mellitus: effects of improved metabolic control and vitamin $\mathrm{E}$ supplementation. Circulation 99(2): 224-229.

7. Shiga T, Imaizumi K, Harada N, Sekiya M (1983) Kinetics of rouleaux formation using TV analyzer. 1. Human erythrocytes. Am J Physiol 245(2): H252- 258.

8. Stoltz JF (1983) Vascular potential and thrombosis. Thromb Res 5: 73-82.

9. Gilbert RE (2014) The endothelium in diabetic nephropathy. Curr Atheroscler Rep 16: 410.

10. Frati Munari AC (2014) Medical significance of endothelial glycocalyx. Part 2: Its role in vascular diseases and in diabetic complications. Arch Cardiol Mex 84(2): 110-116.

11. Redondo-Horcajo M, Lamas S (2005) Oxidative and nitrosative stress in kidney disease: a case for cyclosporine A. J Nephrol 18(4): 453-457.

12. Glorieux G, Cohen G, Jankowski J, Vanholder R (2009) Platelet/Leukocyte activation, inflammation, and uremia. Semin Dial 22(4): 423-427.

13. Hakim RM, Fearon DT, Lazarus JM, Cynthia S Perzanowski (1984) Biocompatibility of dialysis membranes: effects of chronic complement activation. Kidney Int 26(2): 194-200.

14. Thompson S, James M, Wiebe, Brenda Hemmelgarn, Braden Manns, et al. (2015) Cause of death in Patients with Reduced Kidney Function. J Am Soc Nephrol 26(10): 2504-2511.
15. Salvati F, Liani M (2001) Role of platelet surface receptor abnormalities in the bleeding and thrombotic diathesis of uremic patients on hemodialysis and peritoneal dialysis. Int J Artif Organs 24(3): 131-135.

16. Razmara M, Hjemdahl P, Ostenson CG, Li N (2008) Platelet hyperprocoagulant activity in Type 2 diabetes mellitus: attenuation by glycoprotein IIb/IIIa inhibition. J Thromb Haemost 6(12): 2186-2192.

17. Santilli F, Liani R, Di Fulvio P, Formoso G, Simeone P, et al. (2016) Increased circulating resistin is associated with insulin resistance, oxidative stress and platelet activation in type 2 diabetes mellitus. Thromb Haemost 116(6): 1089-1099.

18. Nurden P, NurdenAT (2008) Congenital disorders associated with platelet dysfunctions. Thromb Haemost 99(2): 253-263.

19. Simon P, Ang KS, Cam G (1987) Enhanced platelet aggregation and membrane biocompatibility: possible influence on thrombosis and embolism in hemodialysis patients. Nephron 45(2): 172-173.

20. Berettini M, Buoncristiani U, Parise P, Ballatori E, Nenci GG (1981) Polyacrilonytrile versus cuprophan membranes for hemodialysis: evaluation of efficacy and biocompatibility by platelet aggregation studies. Int J Artif Organs 4(5): 218-222.

21. Di Pietro N, Giardinelli A, Sirolli V, Riganti C, Di Tomo P, et al. (2016) Nitric oxide synthetic pathway and cGMP levels are altered in red blood cells from endstage renal disease patients. Mol Cell Biochem 417(12): 155-167.

22. Cottone $\mathrm{S}$, Lorito $\mathrm{MC}$, Riccobene R, Nardi E, Mulè G, et al. (2008) Oxidative stress, inflammation and cardiovascular disease in chronic renal failure. J Nephrol 21(2): 175-179.

23. Kolluru GK, Bir SC, Kevil CG (2012) Endothelial dysfunction and diabetes: effects on angiogenesis, vascular remodeling, and wound healing. Int J Vasc Med 2012(2012): 30.

24. Brenner BM, Yu AS (1992) Uremic syndrome revisited: a pathogenetic role for retained endogenous inhibitors of nitric oxide synthesis. Curr Opin Nephrol Hypertens 1(1): 3-7. 


\section{Medical Journal of Clinical Trials \& Case Studies}

25. Gertsenshter̆n SY, Panin DN, Pisarenko ON (2009) The effect of external static electric fields on blood flow in fine vessels. Doklady Physics 54(5): 230-232.

26. De Lorenzo A, Martinoli R, Carbonelli MG, Monteleone G, Di Lorenzo N, et al. (2004) Resting metabolic rate incremented by pulsating electrostatic field (PESF therapy). Diabetes Nutr Metab 17(5): 309-312.

27. Hoffstad O, Mitra N, Walsh J, Margolis DJ (2015) Diabetes, lower-extremity amputation, and death. Diabetes Care 38(10): 1852-1857.

28. Liani M, Trabassi E, Cusaro C, Zoppis E, Maduli E, et al. (2014) Effects of a pulsatile electrostatic field on ischemic injury to the diabetic foot: evaluation of refractory ulcers. Primary Care Diabetes 8(3): 244249.

29. Lavery LA, Armstrong DG, Harkless LB (1996) Classification of diabetic foot wounds. J Foot Ankle Surg 35(6): 528-531.

30. Myles AM, Wink DA, Cook JC, Grisham MB (1996) Determination of nitric oxide using fluorescence spectroscopy. Methods Enzymol 268: 105-120.

31. Becker RO, Seldon G (1985) The Body Electric. Morrow, New York.

32. Nuccitelli R, Nuccitelli P, Li C, Narsing S, Pariser DM, et al. (2011) The electric field near human skin wounds declines with age and provides a noninvasive indicator of wound healing. Wound Repair Regen 19(5): 645-655.

33. Bertoluzzo SM, Bollini A, Rasia M, Raynal A (1999) Kinetic model for erythrocyte aggregation. Blood Cells Mol Dis 25(5-6): 339-349.

34. Gargiulo G, Labanca F, Lapi D, Oliviero R, Quarto E, et al. (2008) The effects of treatment with pulsating electrostatic fields on cutaneous microvascular flowmotion patterns. 5th Conference of the European Study Group on Cardiovascular Oscillations, Parma.

35. Tecilazich F, Thanh D, Pradhan-Nabzdyk L, Ermelindo Leal, Ana Tellechea, et al. (2013) Role of endothelial progenitor cells and inflammatory cytokines in healing of diabetic foot ulcers. PLoS One 8(12): e83314.

36. Becker BF, Chappell D, Bruegger D, Annecke T, Jacob $M$ (2010) Therapeutic strategies targeting the endothelial glycocalyx: acute deficits, but great potential. Cardiovasc Res 87(2): 300-310.

37. Hopper RA, VerHalen JP, Tepper O, Mehrara BJ, Detch $\mathrm{R}$, et al. (2009) Osteoblasts stimulated with pulsed electromagnetic fields increase HUVEC proliferation via a VEGF-A independent mechanism. Bioelectromagnetics 30(3): 189-197.

38. Badal SS, Danesh FR (2012) Strategies to reverse endothelial dysfunction in diabetic nephropathy. Kidney Int 82(11): 1151-1154.

39. Fraccalvieri M, Salomone M, Zingarelli EM, Rivarossa F, Bruschi S (2015) Electrical stimulation for difficult wounds: only an alternative procedure? Int Wound J 12(6): 669-673.

40. Liani M, Salvati F, Tresca E, Di Paolo G, Vitacolonna L, et al. (1996) Arteriovenous fistola obstruction and expression of platelet receptors for von Willebrand factor and for fibrinogen (glycoproteins GPIb and GPIIb/IIIa) in haemodialysis patients. The Int J Artificial Organs 19(8): 451-454.

41. Margolis DJ, Gupta J, Hoffstad O, Maryte Papdopoulos, Henry A Glick, et al. (2013) Lack of effectiveness of hyperbaric Oxygen therapy for the treatment of diabetic foot ulcer and the prevention of amputation. Diabetes Care 36(7): 1961-1966.

42. Becker BF, ChappellD, JacobM (2010) Endothelial glycocalyx and coronary vascular permeability: the fringe benefit. Basic Res Cardiol 105(6): 687-701.

43. Drake-Holland AJ, Noble MI (2009) The important new drug target in cardiovascular medicine the vascular glycocalyx. Cardiovasc Hematol Disord drug Targets 9(2): 118-123.

44. Noble MIM, Drake-Holland AJ, Vink H (2008) Hypothesis: arterial glycocalyx dysfunction is the first step in the atherothrombotic process. QJM 101(7): 513-518.

45. Davison D, Basu RK, Goldstein SL, Chawla LS (2014) Fluid management in adults and children: core curriculum. Am J Kidney Dis 63(4): 700-712.

46. Chappell D, Westphal M, Jacob M (2009) The impact of the glycocalyx on microcirculatory oxygen distribution in critical illness. Curr Opin Anaesthesiol 22(2): 155-162. 


\section{Medical Journal of Clinical Trials \& Case Studies}

47. Nieuwdorp M, Mooij HL, Kroon J, Atasever B, Spaan JA, et al. (2006) Endothelial glycocalyx damage coincides with microalbuminuria in type I diabetes. Diabetes 55(4): 1127-1132.

48. Alphonsus CS, Rodseth RN (2014) The endothelial glycocalyx: a review of the vascular barrier. Anaesthesia 69(7): 777-784.

49. Satoh M, Imaizumi $K$, Bessho $T$, Shiga $T$ (1984) Increased erythrocyte aggregation in diabetes mellitus and its relationship to glycosylated haemoglobin and retinopathy. Diabetologia 27(5): 517-521.

50. Deregibus MC, Cantaluppi V, Calogero R, Lo Iacono M, Tetta C, et al. (2007) Endothelial progenitor cell derived microvesicles activate an angiogenic program in endothelial cells by a horizontal transfer of mRNA. Blood 110(7): 2440-2448.

51. Siti HN, Kamisah Y, Kamsiah J (2015) The role of oxidative stress, antioxidants and vascular inflammation in cardiovascular disease (a review). Vascul Pharmacol 71: 40-56.
52. Kong X, Chen L, Ye P, Wang Z, Zhang J, et al. (2016) The role of HYAL2 in LSS-induced glycocalyx impairment and the PKA-mediated decrease in eNOSSer633 phosphorylation and nitric oxide production. Mol Biol Cell 27(25): 3972-3979.

53. Ghiadoni L, Cupisti A, Huang Y, Mattei P, Cardinal H, et al. (2004) Endothelial dysfunction and oxidative stress in chronic renal failure. J Nephrol 17(4): 512519.

54. Stupp R, Taillibert S, Kanner AA, Kesari S, Steinberg DM, et al. (2015) Maintenance Therapy With TumorTreating Fields Plus Temozolomide vs Temozolomide Alone for Glioblastoma: A Randomized Clinical Trial. JAMA 314(23): 2535-2543.

55. Spring S, Simon R, van der Loo B, Kovacevic T, Brockes C, et al. (2008) High-dose atorvastatin in peripheral arterial disease (PAD): effect on endothelial function, intima-media-thickness and local progression of PAD. An open randomized controlled pilot trial. Thromb Haemost 99(1): 182-189. 